\title{
Endothelium-Dependent Relaxations of Piglet Pulmonary Arteries Augment with Maturation
}

\author{
THOMAS M. ZELLERS ${ }^{1}$ AND PAUL M. VANHOUTTE ${ }^{2}$
}

Department of Pediatrics, Section of Cardiology, and Department of Physiology and Biophysics, Mayo Clinic and Foundation, Rochester, Minnesota 55905

\begin{abstract}
To determine whether maturation alters endothelium-dependent responses in porcine pulmonary arteries, rings, with and without endothelium, of small pulmonary arteries taken from piglets of 3,10 , and $30 \mathrm{~d}$ of age were suspended in organ chambers filled with buffered salt solution, bubbled with $95 \% \mathrm{O}_{2}-5 \% \mathrm{CO}_{2}$, and maintained at $37^{\circ} \mathrm{C}$. These studies were performed in the presence of indomethacin $\left(10^{-5} \mathrm{M}\right)$ to inhibit prostaglandin synthesis. In rings without endothelium, potassium chloride $\left(10^{-2}\right.$ to $\left.8.5 \times 10^{-2} \mathrm{M}\right)$ and histamine $\left(10^{-9}\right.$ to $10^{-5}$ $M)$ caused concentration-dependent contractions. When normalized to maximal contractions achieved to each agonist, the concentration-effect curves to potassium chloride and histamine in rings without endothelium were similar at each age. Rings with endothelium showed a progressive shift to the right of the concentration-effect curve to histamine, possibly secondary to an increase in the basal release of, or responsiveness to, the endothelium-derived relaxing factor with maturation. Relaxations to sodium nitroprusside $\left(10^{-9}\right.$ to $\left.10^{-5} \mathrm{M}\right)$ were unaffected by age. In precontracted rings, acetylcholine $\left(10^{-9}\right.$ to $\left.10^{-6} \mathrm{M}\right)$, bradykinin $\left(10^{-10}\right.$ to $\left.10^{-6} \mathrm{M}\right)$, and the calcium ionophore A23187 $\left(10^{-9}\right.$ to $\left.10^{-6} \mathrm{M}\right)$ caused relaxations in rings with endothelium, but not in those without endothelium, which were greater at 10 and $30 \mathrm{~d}$ compared to $3 \mathrm{~d}$; further augmentation at $30 \mathrm{~d}$ compared to $10 \mathrm{~d}$ was not observed. In rings without endothelium, changes in the responsiveness to nitric oxide $\left(10^{-9}\right.$ to $\left.10^{-5} \mathrm{M}\right)$, one of the proposed endothelium-derived relaxing factors, with age were comparable to those observed with endothelium-dependent relaxing agents. These studies demonstrate that endothelium-dependent relaxations increase with age, possibly due to changes in sensitivity of the smooth muscle to the endothelium-derived relaxing factor. (Pediatr Res 30: 176180, 1991)
\end{abstract}

\section{Abbreviations}

EDRF, endothelium-derived relaxing factor

Most mammals, including swine, exhibit elevated pulmonary arterial pressures and resistance in utero that decrease after birth in response to an increase in oxygen tension, vascular remodel-

Received June 15, 1990; accepted April 15, 1991.

Correspondence: Thomas M. Zellers, M.D., Department of Pediatrics, Division of Cardiology, University of Texas Southwestern Medical Center, 5323 Harry Hines Blvd., Dallas, TX 75235

Supported in part by a grant from the National Institutes of Health (HL31183)

'Current address: Department of Pediatrics, Division of Cardiology, University of Texas Southwestern medical Center, Dallas, TX 75235.

Current address: Director, Center for Experimental Therapeutics, Baylor College of Medicine, 1 Baylor Plaza, Houston, TX 77030. ing, and intrapulmonary production of prostaglandins (1-4). The exact mechanisms by which these stimulants induce the observed hemodynamic changes are unclear. However, endothelial cells from pulmonary vessels of most mammals (including humans) contain enzymes that activate or degrade potent vasoactive hormones such as angiotensin I and bradykinin, respectively (5). In addition, the endothelium synthesizes and releases prostacyclin and EDRF when exposed to acetylcholine, bradykinin, and other autocoids; these vasoactive substances contribute to the local regulation of vascular tone (6-13). Cherry and Gillis (14) have shown that the release of an EDRF, other than prostacyclin, can reduce pulmonary artery pressure and resistance in situ. The purpose of our study was to determine if a maturational change in the release and/or effect of EDRF from small porcine pulmonary arteries occurs during the neonatal period.

\section{MATERIALS AND METHODS}

Twenty-two white piglets of either sex, from four sows, were studied at $3(n=6), 10(n=7)$, and $30(n=9) \mathrm{d}$ of age. The piglets were anesthetized with ketamine hydrochloride (Bristol Laboratories, Syracuse, NY), 10 to $15 \mathrm{mg} / \mathrm{kg}$ intramuscularly, and sodium pentobarbital (Fort Dodge Laboratories, Inc., Fort Dodge, IA), 12 to $15 \mathrm{mg} / \mathrm{kg}$ i.v., and exsanguinated in accordance with NIH guidelines for humane care. The heart and lungs were removed en bloc and placed in cold modified Krebs-Ringer bicarbonate solution of the following composition $(\mathrm{mM}): \mathrm{NaCl}$ 118.3, $\mathrm{KCl} 4.7, \mathrm{CaCl}_{2} 2.5, \mathrm{MgSO}_{4} 0.7, \mathrm{H}_{2} \mathrm{O} 1.2, \mathrm{KH}_{2} \mathrm{PO}_{4} 1.2$, $\mathrm{NaHCO}_{3} 25.0$, Ca EDTA 0.026, and glucose 11.1 (control solution).

The intralobar pulmonary arteries, taken just distal to the branch point in the lower lobes (5th order), were dissected free from the surrounding lung parenchyma, cut into rings (3-4 mm long), and cleaned of loose connective tissue, taking special care not to touch the luminal surface. The diameter of the rings varied with age, averaging (nonstretched, measured by microscopy) 0.7 $\pm 0.1 \mathrm{~mm}$ at $3 \mathrm{~d}, 0.8 \pm 0.15 \mathrm{~mm}$ at $10 \mathrm{~d}$, and $1.5 \pm 0.4 \mathrm{~mm}$ at $30 \mathrm{~d}$. In some rings, the endothelium was deliberately removed by gently rubbing the luminal surface with a thin $(0.25-\mathrm{mm})$ stainless steel wire while rolling the vessel on thin tissue wetted with control solution. The rings were then suspended between two stainless steel stirrups; one was connected to a fixed stirrup within the organ chamber and the other to a force transducer (model no. UTC2; Gould Inc., Cleveland, OH) for recording isometric tension. The rings were then placed in organ chambers filled with $25 \mathrm{~mL}$ of control solution, bubbled with $95 \% \mathrm{O}_{2}-5 \%$ $\mathrm{CO}_{2}$, and maintained at $37^{\circ} \mathrm{C}$. Immediately after mounting, the rings were stretched progressively until a maximal response to $\mathrm{KCl}(20 \mathrm{mM})$ was achieved (optimal length/tension relationship). The rings were incubated with indomethacin $\left(10^{-5} \mathrm{M}\right)$ and allowed to equilibrate for $40 \mathrm{~min}$ before further experimentation. Rings with and without endothelium were studied in parallel.

Histology. At the end of each experiment, rings with and without endothelium were fixed in $10 \%$ buffered formalin solu- 
tion $(\mathrm{pH}=7.0)$ for at least $24 \mathrm{~h}$, embedded in paraffin (tissue prep 2; Fair Lawn, NJ), cut into 5- $\mu \mathrm{m}$ sections, and stained with hematoxylin and eosin. The slides were studied under light microscopy. The presence or absence of endothelium and the integrity of the basement membrane, internal elastic lamina, and vascular smooth muscle were determined (Fig. 1).

Protocols. Contractions were studied in quiescent rings. Concentration-response curves to potassium chloride were determined in rings without endothelium that were previously incubated with phentolamine $\left(10^{-5} \mathrm{M}\right)$ plus propranolol $\left(5 \times 10^{-6}\right.$ $\mathrm{M}$; to prevent the effects of catecholamines released from adrenergic nerve terminals) and indomethacin $\left(10^{-5} \mathrm{M}\right.$; to prevent the formation of vasoactive prostaglandins) for $40 \mathrm{~min}$. Contractions to histamine were studied in rings with and without endothelium, in the presence of indomethacin $\left(10^{-5} \mathrm{M}\right)$. To study relaxations, rings were first incubated with indomethacin for 40 min and then exposed to a concentration of prostaglandin $F_{2 c}$ $\left(10^{-6}\right.$ to $\left.4 \times 10^{-6} \mathrm{M}\right)$ that would cause a contraction equal to $75 \%$ of the maximal response to histamine $\left(10^{-5} \mathrm{M}\right.$; determined in all rings). Concentration-response curves to the vasodilators were obtained after the prostaglandin contraction reached a steady state. Rings that did not develop at least $200 \mathrm{mg}$ of tension were excluded from the analysis because these were considered to have damaged smooth muscle. Rings with endothelium were exposed to a single dose of bradykinin $\left(10^{-7} \mathrm{M}\right)$ during lengthtension testing, and those rings that did not achieve at least $30 \%$ relaxation of the maximal histamine contraction were excluded from the experiment. Relaxations to acetylcholine, bradykinin, and the calcium ionophore A23187 were studied in rings with

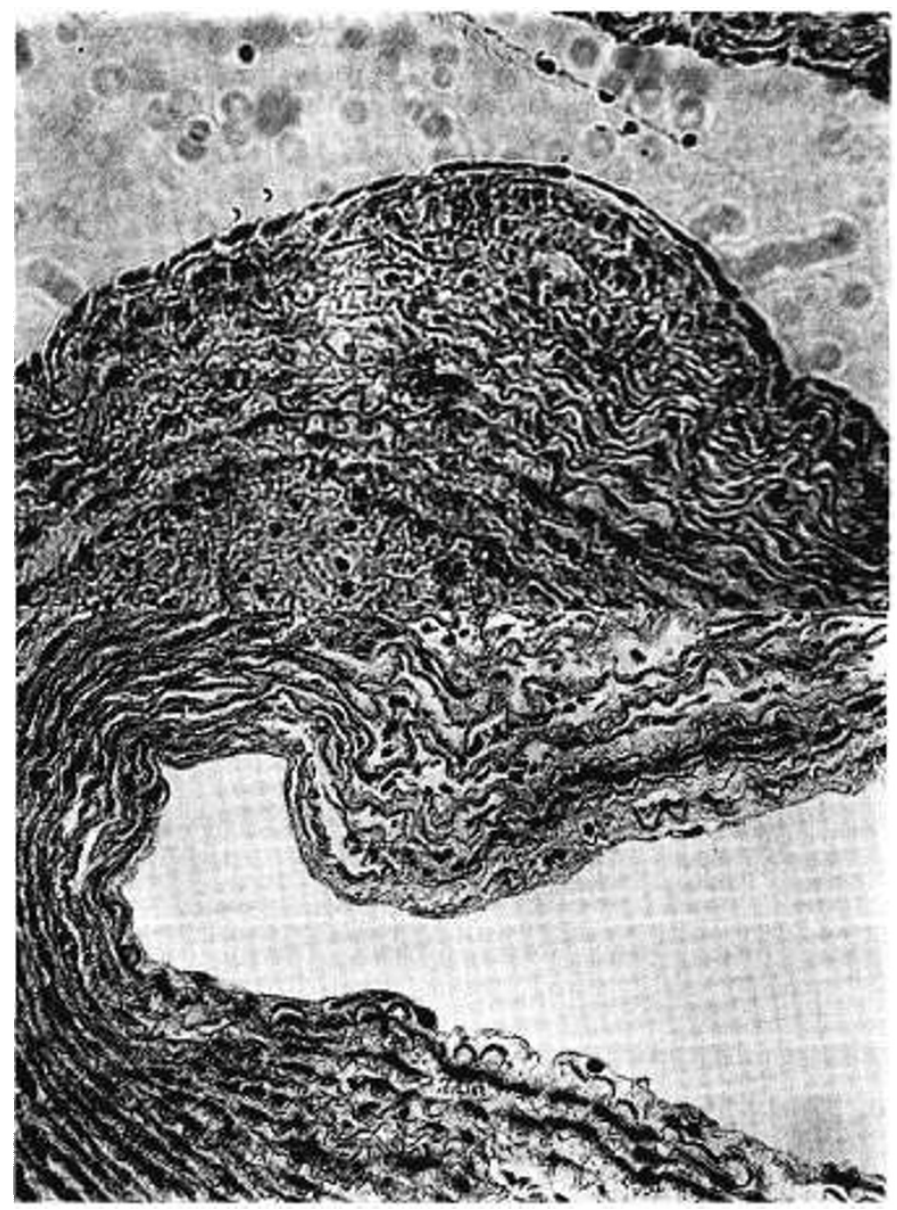

Fig. 1. Histologic sections of neonatal pulmonary artery with and without endothelium. The tissue has been stained with hematoxylin and eosin. The rings with endothelium (top panel) have a layer of endothelial cells present, whereas those without endothelium (bottom panel) are missing this intimal layer. and without endothelium, and those to sodium nitroprusside and solutions of nitric oxide (one of the proposed EDRF) (1518) were determined in rings without endothelium.

Drugs. The following drugs were used: acetylcholine, bradykinin, the calcium ionophore A23187, histamine hydrochloride, indomethacin, DL-propranolol hydrochloride, prostaglandin $\mathrm{F}_{2 \mathrm{c}}$, sodium nitroprusside (all from Sigma Chemical Co., St. Louis, $\mathrm{MO}$ ), and phentolamine mesylate (Ciba-Geigy, Co., Summit, $\mathrm{NJ})$. Indomethacin was first dissolved with $\mathrm{Na}_{2} \mathrm{CO}_{3}\left(10^{-5} \mathrm{M}\right)$, and the calcium ionophore A23187 was dissolved in $100 \mu \mathrm{L}$ of DMSO. All drugs were prepared daily with distilled water and kept on ice throughout the experiment. All drug concentrations are expressed as final molar (M) concentrations in the organ bath solution.

Nitric Oxide. A gas bulb fitted with a silicon rubber injection septum was filled with nitric oxide from a cylinder (Union Carbide, Chicago, IL). An appropriate volume (10-1000 $\mu \mathrm{L})$ was removed with a syringe and injected into another gas bulb filled with $100 \mathrm{~mL}$ of distilled water $\left(37^{\circ} \mathrm{C}\right)$, which has been gassed with helium for $3 \mathrm{~h}$, giving stock solutions of nitric oxide of $4 \times$ $10^{-6} \mathrm{M}, 4 \times 10^{-5} \mathrm{M}$, and $4 \times 10^{-4} \mathrm{M}$ as estimated by the solubility constant of $4.6 \mathrm{~mL} / 100 \mathrm{~mL}$ for nitric oxide. Appropriate volumes of the stock solutions were then withdrawn and added to the organ baths in increasing concentrations in a noncumulative manner.

Statistical analysis. In all experiments, $n$ equals the number of animals from which the rings were taken. Results are expressed as means \pm SEM. Statistical analysis was performed on paired rings (with and without endothelium) using two-tailed $t$ test for paired observations. To compare rings from animals of different age groups, an analysis of variance with Scheffe's test was used. Values were considered statistically significant when $p$ was less than 0.05 .

\section{RESULTS}

Histology. All vessels used were musculoelastic arteries. Rings with endothelium were found to have an intact endothelial layer with the exception of loss of endothelial cells where the stirrups were placed. Rings that were purposely denuded had nearly complete removal of the endothelial cell layer as determined by cross and longitudinal sections of the vascular lumen. Multiple sections of each vessel were examined to confirm the absence of the endothelial cell layer. The internal elastic lamina was intact in all rings examined.

Contractions. When normalized to the maximal contractions of the specific agonist, concentration-response curves to potassium chloride $\left(10^{-2}\right.$ to $\left.8.5 \times 10^{-2} \mathrm{M}\right)$ or histamine $\left(10^{-9}\right.$ to $10^{-5}$ $M)$ in rings without endothelium from 3-, 10-, and 30-d-old piglets were comparable (Figs. 2 and 3). Rings with endothelium also contracted in a concentration-dependent manner to histamine. When normalized to the maximal contraction, the concentration-response curves to histamine in rings with and without endothelium from 3-d-old piglets were comparable. Compared to rings (from animals of the same age) without endothelium, the concentration-response curves to histamine were shifted rightward significantly for rings with endothelium at both 10 and $30 \mathrm{~d}$; concentration-response curves for rings from 30-d-old piglets were shifted rightward significantly more than those observed at $10 \mathrm{~d}$ (Fig. 3).

When expressed in absolute terms, as grams of tension developed, potassium chloride caused contractions that were statistically similar in rings without endothelium taken from 3- and 10d-old piglets; contractions in rings from 30-d-old piglets were significantly greater than those observed at 3 or $10 \mathrm{~d}$ (Fig. 2).

Histamine-induced contractions, at 3 and $10 \mathrm{~d}$, when expressed as grams of tension developed, exhibited a pattern in the concentration-response curves similar to that observed when these data were normalized to maximal contraction. At $30 \mathrm{~d}$, the contractions to histamine were significantly larger than those 

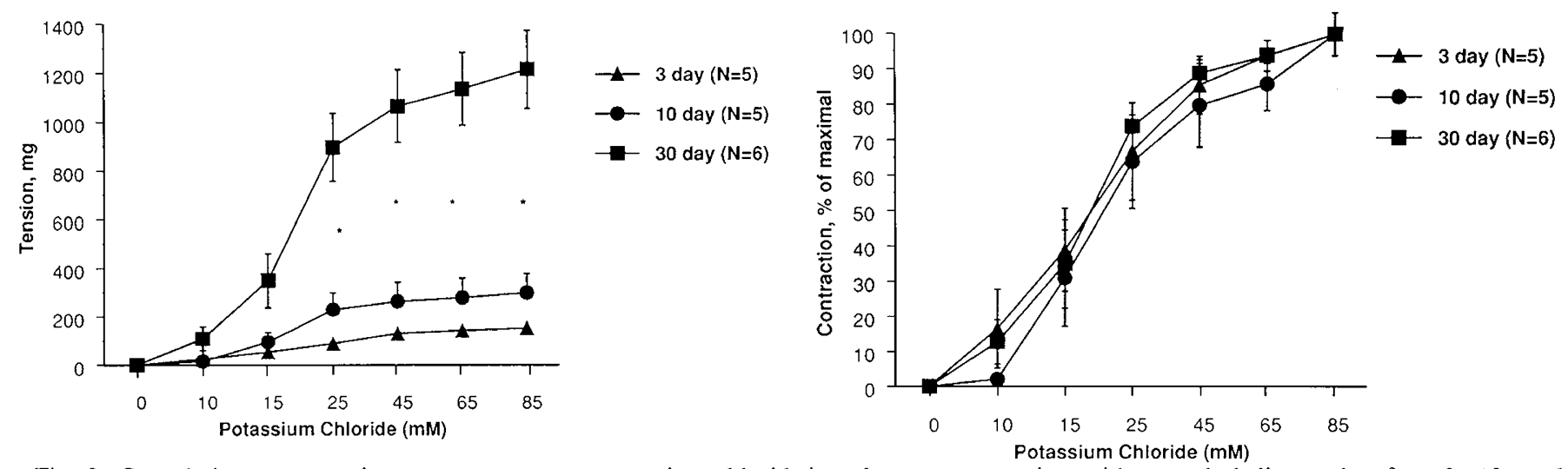

Fig. 2. Cumulative concentration-response curves to potassium chloride in pulmonary artery rings without endothelium, taken from 3-, 10-, and 30-d-old piglets. In the left panel, contractions are expressed in $\mathrm{mg}$ of tension developed to increasing cumulative concentrations of the agonist. In the right panel, these data are normalized to the maximal tension developed by the rings to the agonist and expressed as a percentage of change in tension to increasing cumulative concentrations of potassium chloride. Data are expressed as means \pm SEM. Phentolamine $\left(10^{-5} \mathrm{M}\right)$ and propranolol $\left(5 \times 10^{-6} \mathrm{M}\right)$ were present to prevent the effects of catecholamines released from nerve endings, and indomethacin $\left(10^{-5} \mathrm{M}\right)$ was used to prevent the synthesis of vasoactive prostaglandins.
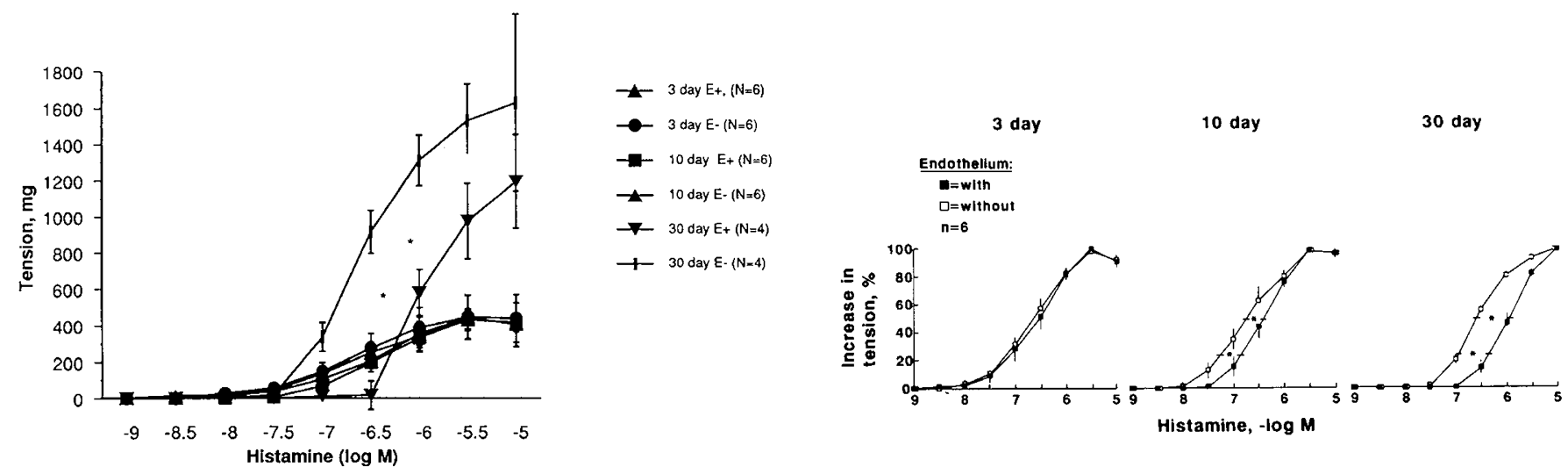

Fig. 3. Cumulative concentration-response curves to histamine in rings with and without endothelium taken from 3-, 10-, and 30-d-old piglets. In the left panel, the effects of increasing cumulative concentrations of histamine $\left(10^{-9}\right.$ to $\left.10^{-5} \mathrm{M}\right)$ are expressed as mg of tension developed to the agonist at each concentration. In the right panel, these data are normalized to the maximal amount tension developed to the highest concentration of the agonist in each individual ring. These data are expressed as the percentage of change (of the maximal contraction) in tension developed at each concentration. Data are expressed as the means \pm SEM. Indomethacin $\left(10^{-5} \mathrm{M}\right)$ was present to prevent synthesis of vasoactive prostaglandins. $M$, molar concentration in the organ bath.

observed at either 3 or $10 \mathrm{~d}$ of age in rings with or without endothelium. At $30 \mathrm{~d}$, the concentration-response curve was shifted rightward for rings with endothelium compared with rings without endothelium, but maximal contractions were not significantly different (Fig. 3).

Relaxations. Sodium nitroprusside $\left(10^{-9}\right.$ to $\left.10^{-5} \mathrm{M}\right)$ caused relaxations in rings without endothelium that were similar in all three age groups (Fig. 4). All rings relaxed $100 \%$ to the agonist.

Acetylcholine $\left(10^{-9}\right.$ to $\left.10^{-6} \mathrm{M}\right)$, bradykinin $\left(10^{-10}\right.$ to $\left.10^{-6} \mathrm{M}\right)$, and the calcium ionophore A23187 $\left(10^{-9}\right.$ to $\left.10^{-6} \mathrm{M}\right)$ caused concentration-dependent relaxations in rings with, but not without, endothelium that were significantly augmented at 10 and $30 \mathrm{~d}$ compared with $3 \mathrm{~d}$ of age (Fig. 5). However, the endothelium-dependent relaxations at $30 \mathrm{~d}$ were not significantly different from those observed at $10 \mathrm{~d}$ of age. The largest relaxations to the above three agonists were also significantly greater at 10 and $30 \mathrm{~d}$ compared with $3 \mathrm{~d}$; the largest relaxations at 10 and 30 $\mathrm{d}$ were statistically similar.

Nitric oxide $\left(10^{-9}\right.$ to $\left.10^{-5} \mathrm{M}\right)$ caused concentration-dependent relaxations in rings without endothelium that were significantly augmented at 10 and $30 \mathrm{~d}$ compared with $3 \mathrm{~d}$ of age (Fig. 5). The direct relaxations evoked by nitric oxide at $30 \mathrm{~d}$ of age were not significantly different from those observed at $10 \mathrm{~d}$ of age. The greatest relaxations to nitric oxide were also significantly augmented at 10 and $30 \mathrm{~d}$ compared with $3 \mathrm{~d}$; the relaxations at 10 and $30 \mathrm{~d}$ were statistically similar.

\section{DISCUSSION}

The endothelium most likely plays a role in the control of vascular tone through the release of EDRF $(12,14,19-27)$. Alterations in the release or effect of EDRF have been demonstrated in animal models of systemic hypertension (28-32). The release of EDRF, other than prostacyclin, may be involved in the control of pulmonary arterial pressure and resistance (14, 33 ). Although the presence of EDRF from pulmonary and systemic vessels of the newborn guinea pig has been recently reported (34), the present experiments suggest a maturational change in the release from or effect of EDRF upon the pulmonary arterial vasculature during the neonatal period.

The contractile response of the vascular smooth muscle is qualitatively similar at 3,10 , and $30 \mathrm{~d}$ of age, as demonstrated by the concentration-response curves of rings without endothelium exposed to potassium chloride and histamine. This suggests that a difference in the contractile capabilities of the vascular smooth muscle or sensitivity to the agonist is not responsible for the augmented endothelium-dependent responses observed with maturation. In contrast, the rightward shift of the concentration- 


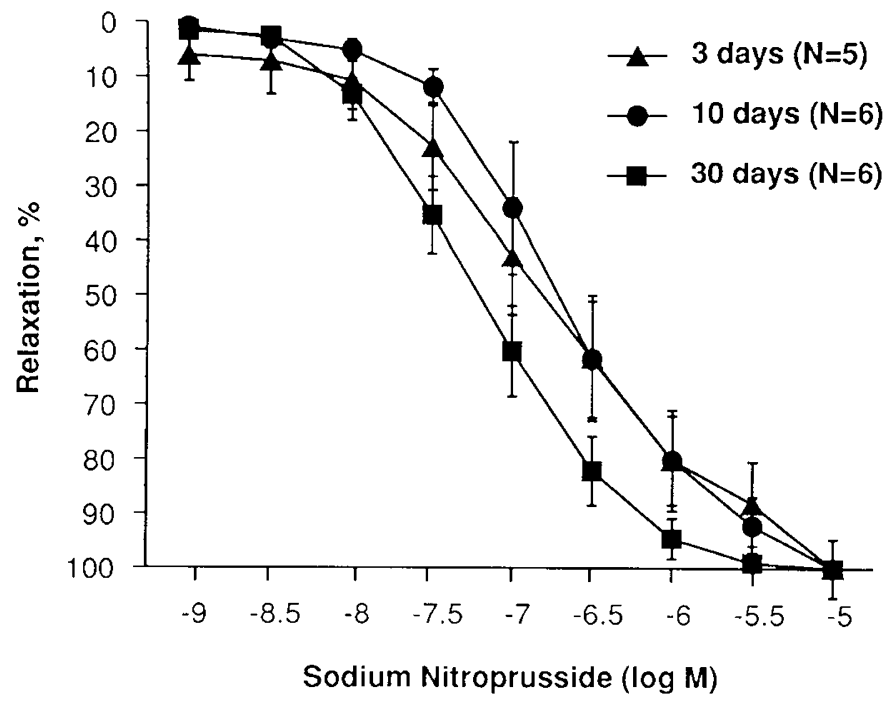

Fig. 4. Cumulative concentration-response curve to sodium nitroprusside in rings without endothelium taken from 3-, 10-, and 30-d-old piglets. The rings were contracted with prostaglandin $F_{2 \alpha}$ to a tension approximating $75 \%$ of the maximal contraction to histamine before exposure to sodium nitroprusside. Relaxations are expressed as the percentage of inhibition of the prostaglandin contraction. Data are expressed as means \pm SEM. Indomethacin $\left(10^{-5} \mathrm{M}\right)$ was present to prevent the synthesis of vasoactive prostaglandins. $M$, molar concentration in the organ bath.

response curve to histamine at 10 and $30 \mathrm{~d}$ of age in rings with, compared to rings without, endothelium suggests a possible maturational increase in basal release $(7,19)$ and/or effect of EDRF. An increased degradation or metabolism of histamine by the endothelial cell or a decreased production of endotheliumderived contracting factors such as superoxide anions $(35,36)$, metabolites of arachidonic acid $(37,38)$, or endothelin, (39) with maturation, are alternate explanations for these observations. A change in histamine metabolism by the endothelial cell is difficult to prove or refute and remains a possible explanation. Superoxide anion production is also possible, but treatment of piglet rings with superoxide dismutase (40) before stimulation with nitric oxide did not alter the responsiveness of these vessels $(n=2$, unpublished observations), making this explanation unlikely. A cyclooxygenase product also is unlikely, inasmuch as all experiments were conducted in the presence of indomethacin. A decreased production of endothelin with time is also possible but untested.

These experiments, more importantly, demonstrate that relaxations to agonists known to stimulate the release of $\operatorname{EDRF}(6,7)$ increase with maturation. The increased relaxations are not due to an altered ability of the vascular smooth muscle to relax, inasmuch as the responses to sodium nitroprusside were similar in vessels taken from piglets from the three age groups. Endogenous release of vasodilator prostaglandins cannot account for these differences because all experiments were performed in the presence of the inhibitor of cyclooxygenase, indomethacin. An increase in receptor number or receptor coupling with maturation also is unlikely because the response to the calcium ionophore A23187, a nonreceptor-mediated agonist, was similar to those observed with the receptor-mediated agonists, acetylcholine and bradykinin. An increased sensitivity of the smooth muscle to, rather than an increased release of, the endothelium-derived factor could explain the increased relaxations because the effect of nitric oxide, one of the proposed $\operatorname{EDRF}(16,17)$, is similar to that observed with acetylcholine, bradykinin, and the calcium ionophore A23187 during the same time course. A maturational increase in the activation of or quantity of soluble guanylate cyclase and, subsequently, cyclic GMP to EDRF may be one of the molecular mechanisms involved (41). The data obtained with
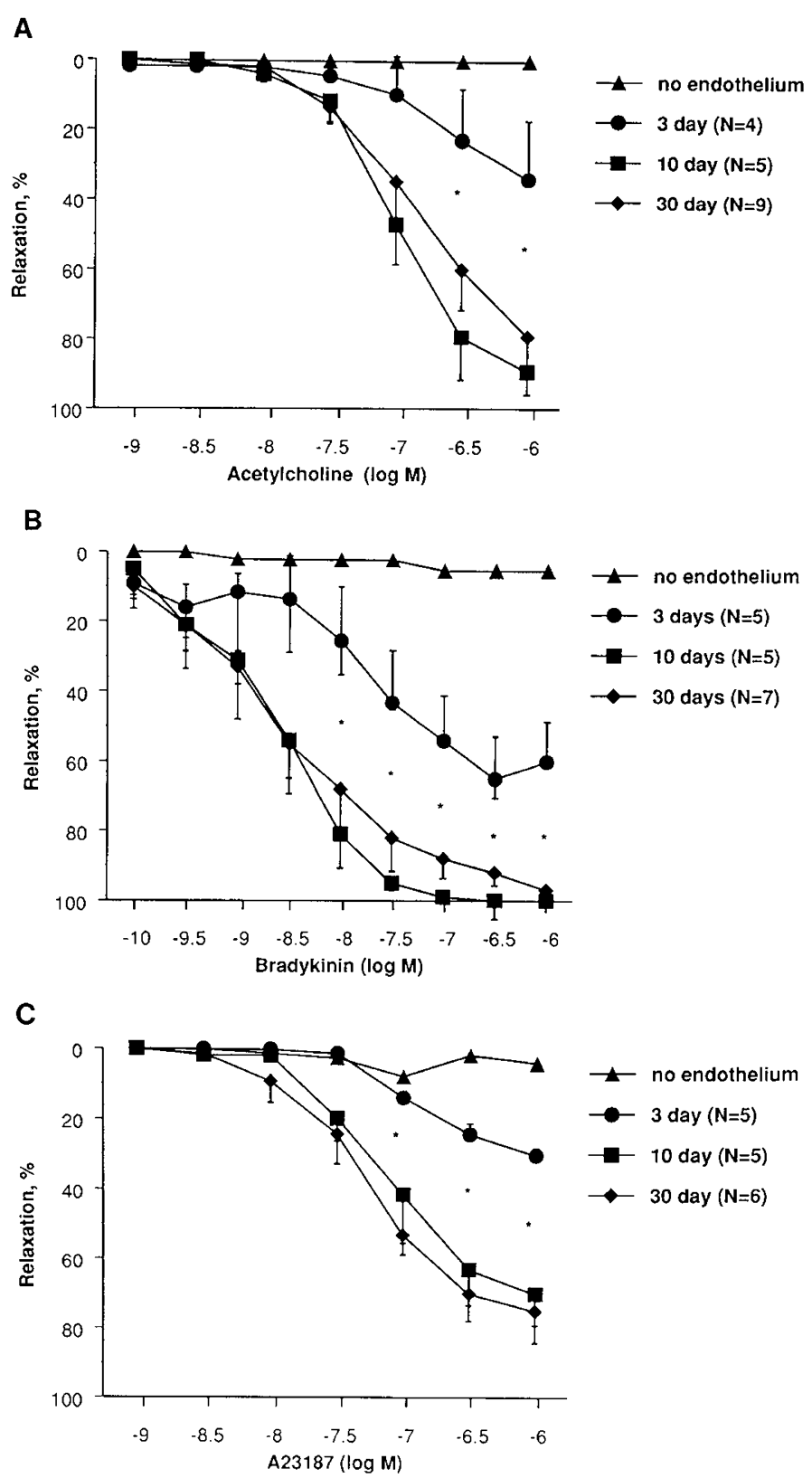

D

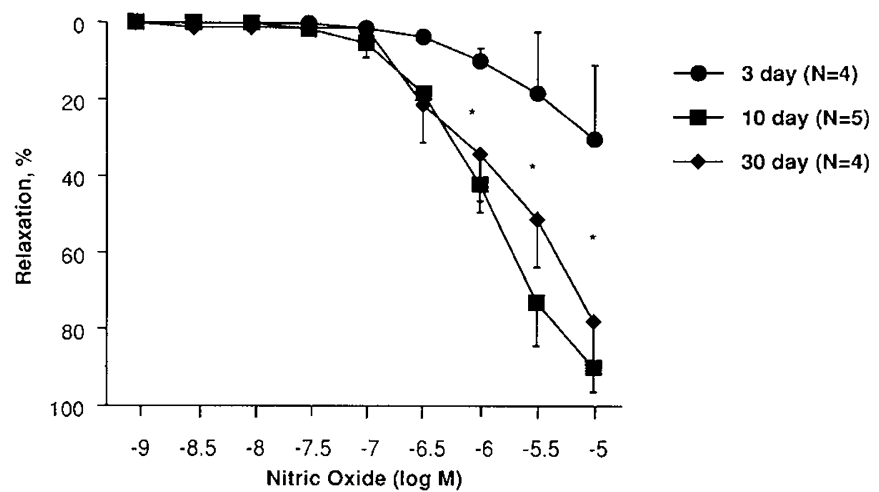

Fig. 5. Cumulative concentration-response curves to acetylcholine $(A)$, bradykinin $(B)$, the calcium ionophore $\mathrm{A} 23187(C)$, and nitric oxide $(D)$ in pulmonary artery rings taken from $3-, 10-$, and 30 -d-old piglets. Rings were contracted with prostaglandin F2 alpha (contraction equal to $75 \%$ of the maximal contraction to histamine), and the relaxations at each age group are expressed as the percentage of inhibition of the prostaglandin contraction. Data are shown as means \pm SEM. Indomethacin $\left(10^{-5} \mathrm{M}\right)$ was present to prevent synthesis of vasoactive prostaglandins. $M$, molar concentration in the organ bath. 
sodium nitroprusside would suggest that this explanation is unlikely because both sodium nitroprusside and nitric oxide activate guanylate cyclase $(16,42)$. However, relaxations evoked by sodium nitroprusside can be mediated by the sodium-potassium ATPase pump $(43,44)$. This additional mechanism may explain the discrepancy between the results observed with nitric oxide and sodium nitroprusside. Alternatively, a concomitant increase in the synthesis and release of the EDRF could also, in part, explain the increase in relaxation to the various endotheliumdependent agonists observed with maturation, but the nitric oxide experiments strongly suggest a maturational change in the sensitivity of the vascular smooth muscle to EDRF.

Physiologically, an increase in the effect or release of EDRF, in both the basal and the stimulated state, may be important to the maintenance of pulmonary vascular tone during the neonatal period. The basal release of EDRF has been demonstrated in arteries from other species $(19,45)$ and is thought to be involved in the maintenance of the basal tone of the blood vessel. A decreased basal release of the endothelium-derived factors, as demonstrated in spontaneously hypertensive rats (28), may help explain the increase in the peripheral resistance characteristic of hypertension. This suggestion is supported by the finding that the antagonist of nitric oxide production, $\mathrm{N}^{\mathrm{G}}$-monomethyl-Larginine, causes sustained increases in peripheral resistance and blood pressure (46). Similarly, the decreased effect of, and possible release of, the EDRF (in the stimulated and possibly in the basal state) at $3 \mathrm{~d}$ compared with 10 and $30 \mathrm{~d}$ observed in the present experiments may be related to the elevated pulmonary pressures and resistance observed in the immediate newborn period in the pig (3); an increased effect or release of EDRF with maturation may play an important role in the perinatal decrease in pulmonary arterial pressure and resistance. Although our results do not definitely demonstrate a causal relationship, they suggest a probable role for EDRF in the process.

\section{REFERENCES}

1. Emmanouilides GC, Moss AJ, Duffie Jr ER, Adams FH 1964 Pulmonary arterial pressure changes in human newborn infants from birth to 3 days of age. J Pediatr 65:327-333

2. Rudolph AM 1979 Fetal and neonatal pulmonary circulation. Ann Rev Physiol 41:383-395

3. Haworth SG, Hislop AA 1981 Adaptation of the pulmonary circulation to extrauterine life in the pig and its relevance to the human infant. Cardiovasc Res 15:108-119

4. Leffler CW, Hessler JR 1981 Perinatal pulmonary prostaglandin production. Am J Physiol 241:H756-H759

5. Dzau VJ 1984 Vascular wall renin-angiotensin pathway in control of the circulation. Am J Med 77:31-36

6. Furchgott RF, Zawadzki JV 1980 The obligatory role of endothelial cells in the relaxation of arterial smooth muscle by acetylcholine. Nature 288:373376

7. Furchgott RF 1983 Role of the endothelium in responses of vascular smooth muscle. Circ Res 53:557-573

8. Moncada S, Vane JR 1978 Prostacyclin $\left(\mathrm{PGI}_{2}\right)$, the vascular wall and vasodilation. In: Vanhoutte PM, Leusen I (eds) Mechanisms of Vasodilation. Karger, Basel, pp 107-121

9. Salzman PM, Salmon JA, Moncada S 1980 Prostacyclin and thromboxane $A_{2}$ synthesis by rabbit pulmonary artery. J Pharmacol Exp Ther 215:240-247

10. Ignarro LJ, Harbison RG, Wood KS, Kadowitz PJ 1986 Activation of purified soluble guanylate cyclase by endothelium derived relaxing factor from intrapulmonary artery and vein: stimulation by acetylcholine, bradykinin, and arachidonic acid. J Pharmacol Exp Ther 237:893-900

11. Chand N, Altura BM 1981 Acetylcholine and bradykinin relax intrapulmonary arteries by acting on endothelial cells: role in lung vascular diseases. Science 213:1376-1379

12. Vanhoutte PM, Rubanyi GM, Miller VM, Houston DS 1986 Modulation of vascular smooth muscle contraction by the endothelium. Annu Rev Physio 48:307-320

13. Furchgott RF, Vanhoutte PM 1989 Endothelium-derived relaxing and contracting factors. FASEB J 3:2007-2018

14. Cherry PD, Gillis CN 1987 Evidence for the role of endothelium-derived relaxing factor in acetylcholine-induced vasodilation in the intact lung. J Pharmacol Exp Ther 241:516-520

15. Furchgott RF 1988 Studies on relaxation of rabbit aorta by sodium nitrate: the basis for the proposal that the acid-activateable inhibitory factor from bovineretractor penis is an organic nitrate and the endothelium-derived relaxing factor is nitric oxide. In: Vanhoutte PM (ed) Vasodilatation: Vascular Smooth Muscle, Peptides, Autonomic Nerves, and Endothelium. Raven Press, New York, pp 401-414

16. Ignarro LJ, Byrus RE, Buga GM, Wood KS 1987 Endothelium-derived relaxing factor from pulmonary artery and vein possesses pharmacologic and chemical properties identical to those of nitric oxide radical. Circ Res 61:866-87

17. Hutchinson PJA, Palmer RMJ, Moncada S 1987 Comparative pharmacology of EDRF and nitric oxide on vascular strips. Eur J Pharmacol 141:445-45

18. Palmer RMJ, Ferrige AG, Moncada S 1987 Nitric oxide release accounts for the biological activity of endothelium-derived relaxing factor. Nature 327:524-526

19. Martin W, Furchgott RF, Villani GM, Lothianandan D 1986 Depression of contractile responses in rat aorta by spontaneously released endotheliumderived relaxing factor. J Pharmacol Exp Ther 237:529-538

20. Busse R, Trogisch G, Bassenge E 1985 The role of the endothelium in the control of vascular tone. Basic Res Cardiol 80:475-490

21. Tesfamarian B, Halpern V, Osol G 1985 Effects of perfusion and endothelium on the reactivity of isolated resistance arteries. Blood Vessels 22:301-305

22. Cohen RA, Shepherd JT, Vanhoutte PM 1983 Inhibitory role of the endothelium in the response of isolated coronary arteries to platelets. Science 221:273-274

23. Luscher TF, Diederich D, Siebenmann R, Lehmann K, Stulz P, Von Segesser L, Yang Z, Turina M, Gradel E, Weber E, Buhler FR 1988 Difference between endothelium-dependent relaxation in arterial and in venous coronary bypass grafts. $N$ Engl J Med 319:462-467

24. Vanhoutte PM 1987 Endothelium and the control of vascular tissue. News Physiol Sci 2:18-22

25. Vanhoutte PM 1989 Endothelium and control of vascular function. Hypertension 13:658-667

26. DeMey J, Vanhoutte PM 1981 Role of the intima in cholinergic and purinergic relaxation of isolated canine femoral arteries. J Physiol 316:347-355

27. DeMey J, Vanhoutte PM 1982 Heterogeneous behavior of the canine arterial and venous wall: importance of the endothelium. Circ Res 51:439-447

28. Luscher TF, Raij L, Vanhoutte PM 1987 Endothelium-dependent vascular responses in normotensive and hypertensive Dahl rats. Hypertension 9(suppl III):III $157-$ III 163

29. Luscher TF, Vanhoutte PM, Raij L 1987 Antihypertensive treatment normalizes decreased endothelium-dependent relaxations in rats with salt-induced hypertension. Hypertension 9(suppl III):III193-III197

30. Winquist RJ, Bunting PB, Boslin EP, Wallace AA 1984 Decreased endothelium-dependent relaxation in New Zealand genetic hypertensive rats. $\mathrm{J}$ Hypertension 2:541-546

31. Lockette W, Otuska Y, Carretero O 1986 The loss of endothelium-dependent vascular relaxation in hypertension. Hypertension 8(suppl II):II61-II66

32. Konishi M, Su C 1983 Role of endothelium in dilator responses of spontaneously hypertensive rat arteries. Hypertension 5:881-886

33. Fritts Jr HW, Harris P, Clauss RH, Odell JE, Cournand A 1958 The effect of acetylcholine on the human pulmonary circulation under normal and hypoxic conditions. J Clin Invest 37:99-110

34. Davidson D, Eldemerdash A 1990 Endothelium-derived relaxing factor: presence in pulmonary and systemic arteries of the newborn guinea pig. Pediatr Res 27:128-132

35. Vanhoutte PM, Katusic ZS 1988 Endothelium-derived contracting factor: endothelin and/or superoxide anion? TIPS 9:229-230

36. Katusic ZS, Vanhoutte PM 1986 Anoxic contractions in isolated canine cerebral arteries. Contribution of endothelium-derived factors, metabolites of arachidonic acid and calcium entry. J Cardiovasc Pharmacol 8:S97-S101

37. Katusic ZS, Shepherd JT, Vanhoutte PM 1988 Endothelium-dependent contractions to calcium ionophore A23187, arachidonic acid and acetylcholine in canine basilar arteries. Stroke 19:476-479

38. Luscher TF, Vanhoutte PM 1986 Endothelium-dependent contractions to acetylcholine in the aorta of the spontaneously hypertensive rat. Hypertension 8:344-348

39. Yanagesawa $M$, Kurihara $H$, Kimura S, Tombe $Y$, Kobayoshi M, Mitsui $Y$, Yasaki Y, Goto K, Musaki T 1988 A novel potent vasoconstrictor peptide produced by vascular endothelial cells. Nature 332:411-415

40. Rubanyi GM, Vanhoutte PM 1986 Superoxide anions and hyperoxia inactivate endothelium-derived relaxing factors. Am J Physiol 250:H822-H827

41. Rapoport RM, Murad F 1983 Agonist-induced endothelium-dependent relaxations in rat thoracic aorta may be mediated through cGMP. Circ Res $52: 352-357$

42. Ignarro LJ, Kadowitz PJ 1985 The pharmacological and physiological role of cyclic GMP in vascular smooth muscle relaxation. Annu Rev Pharmacol Toxicol 25:171-191

43. Rapoport RM, Murad F 1983 Effect of ouabain and alterations in potassium concentration on relaxation induced by sodium nitroprusside. Blood Vessels 20:255-264

44. Rapoport RM, Schwartz K, Murad F 1985 Effect of sodium-potassium pump inhibitors and membrane-depolarizing agents on sodium nitroprusside-induced relaxation and cyclic guanosine monophosphate accumulation in rat aorta. Circ Res 57:164-170

45. Miller VM, Vanhoutte PM 1985 Endothelial alpha-2-adrenoceptors in canine pulmonary and systemic blood vessels. Eur J Pharmacol 118:123-129

46. Rees DD, Palmer RMJ, Moncada S 1989 Role of endothelium-derived nitric oxide in the regulation of blood pressure. Proc Natl Acad Sci USA 86:33753378 